\title{
Óleos essenciais de plantas brasileiras
}

R. DE ALENCAR(1); R. ALVES DE LIMA(1); R. G. CAMPOS CORREA(1); O. R. GOTTLIEB(2); M. C. MARX(2); M. LEĀO DA SILVA(3); J. G. SOARES MAIA(3); M. TAVEIRA MAGALHĀES(4); R. M. VIEGAS ASSUMPÇÃO 5).

\section{SINOPSE}

Como parte de um estudo químico de plantas brasileiras, comunica-se a presença de óleos essenciais na madeira de Dicypellium caryophyllatum Nees (Lauraceae), de composição: eugenol 95,5\% O-metileugenol $1,6 \%$; as fôlhas de Myrcia polyantha D.C., var. coriacea Bg. (Myrtaceae), com um rendimento de $2 \%$, de composição: limoneno $4,5 \%$, nera $128,0 \%$, geranial $40,2 \%$, sesquiterpenos $14,6 \%$; a casca de Parkia oppositifolia Spr. ex Benth. (Leguminose-mimoeoidaeae), de composição: salicilato de metila $98,2 \%$; a madeirado tronco de Dalbergia decipularis Rizz. et Mattos (Leguminosae-Papilic. natae), de composição: nerolidol $97,2 \%$; a madeira do tronco de Poecilanthe parviflora Benth. (Legu. minosae-Papilionatae): nerolidol $26,0 \%$; as fôlhas de Piper cavalcantei Yuncker (Piperaceae), rendimento $1,9 \%$ de composição: safrol $69,0 \%$, metileugenol $8,0 \%$, terpenos $23,0 \%$.

Como parte do levantamento quírnico da flora odorífera brasileira que estamos empreendendo com o objetivo de encontrar novas fontes de produtos aromáticos comercializáveis, apresentamos, no presente trabalho, os resultados referentes a um conjunto de espécies cujo volume de informações é insuficiente para justificar comunicações isoladas.

\section{Discypellium caryophyllatum Nees} (Lauraceae)

O nome popular "cravo do Maranhão" faz alusão ao odor característico da planta. Analisando, por cromatografia gás-líquido (coluna de
Apiezon $\mathrm{M}$, temperatura de $200^{\circ}$ ) e espectrometria de ressonância magnética nuclear, uma amostra de óleo essencial, pressumivelmente da madeira, e que nos foi gentilmente cedida pelo Dr. Alcides d'Andrea Pinto (Instituto Agronômico de Campinas), comprovamos, de fato, a presença de eugenol em alto teor $(95,5 \%)$, ao lado de metileugenol $(1,6 \%)$ e de três outros constituintes menores não identificados.

Parkia oppositiolia Spr. ex-Benth. (Leguminosae-Mimosoideae)

Trata-se de uma planta da Amazônia, popularmente chamada de "faveira benguê", nome certamente alusivo à semelhança olfativa com o antigo produto comercial "bálsamo de benguê", usado contra luxações e outras dores musculares. Análise por cromatografia gáslíquido (coluna de SAIB, temperatura de $160^{\circ}$ ) e espectrometria de ressonância magnética nuclear do óleo essencial de suas cascas, revelou, de fato, a presença quase exclusiva de salicilato de metila $(98,2 \%)$.

Dalbergia decipularis Rizz. et Matt (Leguminosae-Papilionatae)

O jacarandá do Estado da Bahia, popularmente chamado "Sebastião de Arruda", é altamente apreciada pela beleza e a resistência do seu cerne. Constitui artigo de exportação, com seu preço estabelecido por quilo de madeira. Sendo, assim, tão valioso, não poderá constituir

(1) - Universidade Federal do Ceará

(2) - Universidade Federal Rural do Rio de Janeiro.

(3) - Instituto Nacional de Pesquisas da Amazônia.

(4) - Instituto de Tecnologia Alimentar, Ministêrio da Agricultura.

(5) - Instituto de Pesquisas Tecnológicas, Universidade de São Paulo. 
matéria prima para obtenção de óleo essencial. Para registro científico, procedemos assim mesmo à análise do óleo essencial do cerne. Constitui-se êsse óleo de $97,6 \%$ de nerolidol, não sŁndo farnesol o único outro componente presente e não identificado $(2,4 \%)$. A análise foi feita por cromatografia gás-líquido (coluna de Apiezon $\mathrm{M}$, temperatura de $220^{\circ}$ ) e espectrometria de ressonância magnética nuclear.

Entre cêrca de vinte espécies de dalbergias brasileiras que já examinamos, apenas $D$. decipularis contém óleo essencial. Dalbergias também existem na Índia, tendo sido assinalada a presença de nerolidol em D. parviflora Roxb. (Spoelstra, 1931), e D. sisso Roxb. (Kathpalia, 1952) .

\section{Poecilanthe parviflora Benth. (Leguminosae.Papilionatàe)}

Trata-se de uma espécie que ocorre no Estado do Espírito Santo. A sua madeira, usada para a confecção de dormentes de via férrea, é resistente ao ataque de fungos devido à presença de flavanona sacuranetina (Assumpção et alii, 1968) .

O óleo essenciai obtido da madeira foi ane. lisado por cromatografia gás-líquido (coluna de Apiezon, temperatura de $20^{\circ}$ ) e espectrometria de ressonância magnética nuclear. Entre cêrca de nove constituintes, identificou-se nerolidol, na proporção de $26 \%$.

Ambas as leguminosas-papilionáceas aqui referidas contém, assim, quantidades substanciais de nerolidol. De fato, também os gêneros Myroxylon, Myrospermum e Myrocarpus, das quais se obtem nerolidol comercialmente, pertencem a esta subfamília (Naves, 1948).

\section{Myrcia poliantha D.C. var. coriacea $\mathrm{Bg}$. (Myrtaceae)}

Trata-se de uma espécie arbórea, coletada nos arredores de Fortaleza, Estado do Ceará. O seu nome popular "pau santo" deixa prever o seu uso, em medicina popular, para diversos males.

Por arraste a vapor e coobação das águas condensadas, obteve-se das fôlhas um óleo essencial com rendimento de $2 \%$. Análise dêste óleo por espectrometria de ressonância magné- tica nuclear e cromatografia gás-líquido (coluna de Apiezon $\mathrm{M}$, temperatura de $180^{\circ}$ ) permitiu a identificação de limoneno $(4 \%)$, neral $(28 \%)$ e geranial $(50,2 \%)$. Cêrca de $14,6 \%$ do óleo se constitui de sesquiterpenos não identificados.

Êste óleo essencial assemelha-se, razoàvelmente, ao óleo de Eucalyptus staigeriana F.v.M., espécie de origem australiana (Guenther, 1950), aclimatada e explorada industrialmente no Brasil. Por esta razão opina-se que a Myrcia polyantha possa servir para o mesmo fim.

\section{Piper cavalcantei Yuncker (Piperaceae)}

Planta originária da Amazônia, Estado do Acre, é vulgarmente chamada de "panquilé". Forma pequenos arbustos (cêrca de 1.2 metros de altura), bastante ramificados. Os exemplares por nós utilizados originaram-se de Manaus, onde, cultivados em terra fértil, atingiram tamanho acima do normal (cêrca de 1,5 metros de altura). Típica de mata secundária, alastrase facilmente. Os talos apresentam nós a intervalos de uns $15 \mathrm{~cm}$ que servem para o seu replantio.

O rendimento em óleo essencial das fôlhas é da ordem de $2 \%$. Análise por espectrometria de ressonância magnética nuclear e cromatografia gás-líquido (coluna de Apiezon $\mathrm{M}$, temperatura de $180^{\circ}$ ) revelou a presença de $23 \%$ de terpenos, de $8 \%$ de metileugenol e de pelo menos $69 \%$ de safrol.

A principal fonte de safrol no Brasil é o óleo da madeira de sassafrás Ocotea pretiosa (Nees) Mez. Sua produção implica na derrubada de árvores que demandam muitos anos para seu crescimento e que, por isso, são cada vez mais escassas nas poucas florestas do sul do país. Consideramos, assim, altamente promissoras as perspectivas de exploração do "panquilé", uma vez que, ao alto teor de safrol, alia o fato de se tratar de uma planta de ciclo curto, possível de fácil e abundante cultivo.

\section{AGRADECIMENTOS}

Agradecimentos são devidos ao Conselho Nacional de Pesquisas por suporte financeiro ao presente trabalho e às botânicas Carmem Lúcia Falcão Ichaso e Elsie Franklin Guimarães pela classificação do panquilé. 
COMPOSIÇÃO PERCENTUAL DE ALGUNS ÓLEOS ESSENCIAIS BRASILEIROS

\begin{tabular}{|c|c|c|c|}
\hline & & SEPARAÇÃO & IDENTIFICAÇÃO \\
\hline $\begin{array}{l}\text { Dicypellium caryophyllatum } \\
\text { Nees } \\
\text { Eugenol } \\
\text { Metileugenol }\end{array}$ & $\begin{array}{c}\text { MADEIRA } \\
95,5 \\
1,6\end{array}$ & & $\begin{array}{l}\text { CGL, RMN } \\
\text { CGL, RMN }\end{array}$ \\
\hline $\begin{array}{l}\text { Parkia oppositifolia } \\
\text { Spr. ex Benth. } \\
\text { Salicilat ode Mtila }\end{array}$ & $\begin{array}{c}\text { CASCA } \\
98,2\end{array}$ & & CGL, RMN \\
\hline $\begin{array}{l}\text { Dalbergia decipularis } \\
\text { Rizz. et Matt. } \\
\text { Nerolidol }\end{array}$ & $\frac{\text { MADEIRA }}{97,2}$ & & CGL, RMN \\
\hline $\begin{array}{l}\text { Poecilanthe parviflora } \\
\text { Benth } \\
\text { Nerolidol }\end{array}$ & $\begin{array}{c}\text { MADEIRA } \\
26,0\end{array}$ & & CGL, RMN \\
\hline $\begin{array}{l}\text { Myrcia polyantha } \\
\text { D.C., var. coriacea } \mathrm{Bg} \\
\text { Limoneno } \\
\text { Neral } \\
\text { Geranial } \\
\text { Sesquiterpenos }\end{array}$ & $\begin{array}{c}\text { FÔLHA } \\
2,0 \% \\
4,5 \\
28,0 \\
50,2 \\
14,6\end{array}$ & & $\begin{array}{l}\text { CGL } \\
\text { CGL, RMN } \\
\text { CGL, RMN } \\
\text { CGL }\end{array}$ \\
\hline $\begin{array}{l}\text { Piper cavalcantei Yuncker } \\
\\
\text { Terpenos } \\
\text { Safrol } \\
\text { Metileugenol }\end{array}$ & $\begin{array}{c}\text { FÔLHA } \\
1,9 \% \\
23,0 \\
69,0 \\
8,0\end{array}$ & $\begin{array}{l}\text { CGL } \\
\text { CGL }\end{array}$ & $\begin{array}{l}\text { CGL } \\
\text { CGL, RMN } \\
\text { CGL, RMN }\end{array}$ \\
\hline
\end{tabular}

\section{SUMMARY}

As part of a chemical survey of brazilian plants. we report the presence of essential oils in the wood of Dicypellium caryophyllatum Nees (Lauraceae), composition: eugenol 95,5\%, O-methyleugenol $1,6 \%$; the leaves of Myrcia polyantha D.C., var. coriacea $\mathrm{Bg}$. (Myrtaceae), yield: $2 \%$, composition: limonene $4,5 \%$, neral $28,0 \%$, geranial $50,2 \%$, sesquiterpenes 14,6\%; the bark of Parkia oppositifolia Spr. ex Benth. (Leguminosae-Mimosoideae). composition: methyl salicylate $98,2 \%$; the trunk wood of Dalbergia decipularis Rizz. et Mattos (LeguminosaePapilionatae), composition: nerolidol 97,2\%; the trunk wood of Poecilanthe parviflora Benth. (Leguminosae-Papilionatae), composition : nerolidol $26,0 \%$; the leaves of Piper cavalcantei Yuncker (Piperaceae), yield: $1.9 \%$, composition: safrol $69,0 \%$ methyleu genol $8,0 \%$ terpenes $23,0 \%$.

\section{BIBLIOGRAFIA CITADA}

Guentner, E.

1950 - The Essential Oils. New York, D. van Nostrand Co., Inc. v. 4; p. 522.

Kathpalia, Y. P. \& Dutt, S.

1952 - Indian Scap J., $17(285)$.

NAVES, Y. R.

1947 - Helv. Chim. Acta, 30(275)

1948 - Helv. Chim. Acta, 31(408).

Spoelstra, D. B.

1931 - Rec. trav. chim., 50(433)

VIEGAS, R. M. ET ALII

1968 - Anais Acad. brasil. Cien., 40(297). 